\title{
8
}

\section{Technical Education in Jeopardy? Assessing the Interdisciplinary Faculty Structure in a University Merger}

\section{Tea Vellamo, Elias Pekkola, and Taru Siekkinen}

\section{Introduction}

The biggest challenges facing our society today are the so-called wicked problems, which, according to the United Nations, are "related to poverty, inequality, climate, environmental degradation, prosperity, and peace and justice" (The UN Sustainable Development Goals 2015). These global societal problems have also been introduced into the higher education arena through global rankings, such as Times Higher Education, which assesses universities' performance against the UN Sustainable Development Goals.

Universities, which have a key position within societies to produce new knowledge and innovations (Välimaa et al. 2016), answer wicked problems by forming new interdisciplinary structures. Indeed, increased

T. Vellamo $(\bowtie) \bullet$ E. Pekkola

Tampere University, Tampere, Finland

e-mail: tea.vellamo@tuni.fi; elias.pekkola@tuni.fi

T. Siekkinen

University of Jyväskylä, Jyväskylä, Finland

e-mail: taru.siekkinen@jyu.fi 
societal complexity, divergent stakeholder needs and conflicting political values make it impossible to solve these problems solely through rational-technical (Head and Alford 2015) or other discipline-based approaches. Instead of expert-driven rational planning and engineering, wicked problems require collaboration involving different actors and organisations (Head and Alford 2015; Ferlie et al. 2011).

In higher education, interdisciplinarity, which entails breaking down disciplinary boundaries, building on different experiences and perspectives and involving new participants, has been promoted as a means to address wicked problems and produce social innovations (Brown et al. 2010). Educational institutions establish interdisciplinary infrastructures to foster new kinds of collaboration outside the traditional disciplinary fields (Ramaley 2014). University mergers are also used to challenge the traditional disciplinary structures and encourage new innovative epistemological approaches by forming larger and more complex interdisciplinary higher education institutions. In addition, institutions create interdisciplinary units through organisational restructuring (Geschwind 2018).

Technical disciplines and engineering are crucial to solving many wicked problems. According to critics of rational-technical approaches, a paradigm shift is needed in technical education. Along with external stakeholders and other disciplines, technical education could eschew tradition and find better ways to tackle these wicked problems (Head and Alford 2015, 712).

In this chapter, we analyse a multidisciplinary, sector-breaking merger of three higher education institutions in the Tampere City region. The strategy of this new university consortium is to combine education and research on technology, society and health to create an interdisciplinary approach for solving wicked problems. The three institutions, which merged in 2019, include a single field technical university, Tampere University of Technology (TUT), and a comprehensive university, the University of Tampere (UTa), forming a new university, Tampere University. The new university owns the Tampere University of Applied Sciences (TAMK), thus forming a university consortium.

The new university adopts a "multidisciplinary approach [which] will not only deliver more effective responses to global challenges but also 
open up new opportunities for science and its applications" (Tampere University web page-https:/www.tuni.fi/en/news/together-we-aregreater). Interdisciplinarity has been chosen as a transformation strategy in the university's organisational reform. Tampere University strategy states, "[w]e recognise and know how to systematically anticipate the most demanding global, national and regional phenomena, challenges and opportunities." This occurs through "[c]lose and well-organised interaction with stakeholders and multidisciplinary research and development platforms and programmes that combine different disciplines ..." (Tampere3 strategy 2 Feb 2018). In practice, this includes establishing new interdisciplinary faculty structures to increase interaction between different fields. Multiple disciplinary views and boundary-crossing cooperation should increase the social relevance of technical education and enhance its capacity to address wicked problems. However, this may challenge the identity of technical education and affect its role in the eyes of stakeholders.

Here, we analyse the new university's interdisciplinary faculty structure plans and their justifications and examine them from the perspective of technical education. The empirical data consist of three subsequent proposals for the new faculty structure by the University Consortium Transitionary Board, the official statements of different internal organs of technical education and open feedback from the higher education institutions' staff and students collected through an electronic questionnaire. The Transitionary Board members represent the highest level of domestic and international expertise in the fields of science and the arts at the university and in industry. According to the Board, the interdisciplinary faculty structure arises from the new university's strategy and educational needs, as interdisciplinary approaches are better for addressing wicked problems. Staff and students commented on the effects they thought the new interdisciplinary structure would have on technical education and its responsiveness to its stakeholders. To identify the anticipated effects of the interdisciplinary organisational structure on technical education, we asked the following question:

- How are the potential benefits and risks of the new interdisciplinary faculty structure for the different stakeholders of technical education represented in the feedback? 
First, we identify the different stakeholders presented in the feedback. After which, we examine how the interdisciplinary structure is considered to affect the stakeholders and the university's responsibilities towards them. There is a tension between the aims of the new structure and how representatives of the technical fields think the university should be responsible to its stakeholders from a disciplinary perspective. Since the rhetoric and supporting theories extol the virtues of an interdisciplinary approach, we are interested in the possible threats this new structure creates for technical education. We seek to determine whether the proposed interdisciplinary structure is perceived to jeopardise the identity, responsiveness to stakeholders and social relevance of technical education.

\section{Data Collection and Analysis}

The Transitional Board of Tampere University is an external and independent organ comprising representatives with academic backgrounds in the university's disciplines and major industrial stakeholders. According to the Board, the faculty structure was meant to be ground-breaking by combining the focus areas of the new university in an interdisciplinary way and based on the needs of teaching. In addition, the Board aimed to produce a well-balanced, administratively functional faculty structure (slides on the first proposal 24 Nov 2017).

During the process, the Board made two proposals for the faculty structure, receiving 700 and 400 comments, respectively (see Appendix 2 ). We received permission from the Tampere 3 project organisation to use the proposals, the official comments and the staff and student comments collected through online questionnaires. The questionnaires were completed anonymously, so it is impossible to determine whether they are from students or staff or from which institution.

The data were analysed using two methods of qualitative analysis. First, a conventional content analysis was performed, which is appropriate when the aim of the study is to describe the phenomenon and where the categories arise from the data (Hsieh and Shannon 2005). In addition, we employed the ideas of thinking with theory, where qualitative data are 
analysed based on prior research (Jackson and Mazzei 2012). In practice, employing these two methods meant that the categories arose from the data, although the researchers also applied their previous knowledge of the subject and theories during the analysis process. The relevant theories included university social responsibility and stakeholder theory and theories of disciplinarity. These theories were selected because university social responsibility is related to the aims of sustainability and addressing wicked problems while acknowledging the responsibility of higher education to its different stakeholders. Disciplinarity and the different disciplinary approaches illuminate the chosen interdisciplinary structure and its underlying theoretical implications. In addition, disciplinary theories are a basis for academic identities (Becher and Trowler 2001; Ylijoki and Ursin 2013).

\section{Social Responsibility of Universities}

The requirement for social relevance is one of the biggest challenges in higher education (Kogan and Teichler 2007). The function of universities in society is related to creating knowledge, fostering innovations and producing a skilled workforce to meet the needs of society. Knowledge creation is emphasised to be collaborative, breaking down institutional and disciplinary boundaries, and universities have a central function in this regard (Gibbons et al. 1994; Välimaa et al. 2016). Higher education should increasingly involve external stakeholders in research and teaching activities and higher education institutions and their larger communities engage in beneficial knowledge exchange and the reciprocal exchange of resources (Van de Ven 2007; Ramaley 2014). However, as Van de Ven (2007) argues, there is a relevance gap between the theoretical academic research produced in universities and the needs of stakeholders in society for applicable knowledge. New models for collaboration between educational institutions and broader society also have different implications for research, teaching, learning, curricula and the structure of institutions (Ramaley 2014). Accordingly, the academic disciplinary approach may be inadequate for meeting stakeholders' needs for applicable knowledge. 
Responsibility in higher education is an elusive concept. Vasilescu et al. $(2010,4177)$ view universities' social responsibility as "part of the debate about competitiveness and sustainability in the globalization context." Universities strive to become responsible because of moral and legal requirements or to gain competitive edge in marketing the university brand and to maintain their institutional legitimacy and funding (Wan Saiful 2006). The concept of university social responsibility is also closely tied to the concept of stakeholder (Tetrevova and Sabolova 2010). When discussing responsibility and its different aspects, we ask to whom the university is responsible and how. There are multiple stakeholders with either complimentary or conflicting interests in the university. Based on the literature on higher education stakeholder theories (Esfijani et al. 2013; Chapleo and Simms 2010; Tetrevova and Sabolova 2010; Benneworth and Jongbloed 2010; Lyytinen et al. 2017), we can summarise and group actual or potential university stakeholders as follows:

- Students, applicants, graduates

- Staff, employees, academics or non-academics

- Industry, business

- Government on central, regional and local levels

- Other (higher education) institutions as competitors or partners

- Society

- Community

- Funders, grant agencies, sponsors, suppliers

- Environmental groups, consumer groups

- General public, taxpayers

There are different views on the most important stakeholders in public universities. Benneworth and Jongbloed (2010) see government as the most important stakeholder, as it is the major funder of public higher education. However, due to changed funding mechanisms and increased demand for societal impact, external stakeholders have gained importance. Universities are responsible to companies and industry for research and development cooperation and for providing workforce with the needed skills and knowledge; to students, for providing them with relevant degree education; and more generally, to the whole academic community 
(staff, academics, employees), for providing the conditions and resources for teaching and research as well as institutional reputation and acclaim. Maintaining the university's rank and prestige is not only an intra-institutional responsibility but also an aspect of national and international competitiveness. Environmental responsibility is also important, as universities are indispensable producers of knowledge for solving serious ecological problems. The ways in which a university strives to be responsible to its different stakeholders affect not only its education, research and other actions but also its strategy and organisational structure. Chapleo and Simms $(2010,6)$ state "a stakeholder group's impact on funding and policies of the university were consistently highlighted as key" as well as "their ability to make demands on the university by their expectations." Thus, universities respond to the needs of the stakeholders, while stakeholders also influence university strategies, policies and structures.

\section{The Transition Beyond Disciplinarity}

The Transitionary Board of Tampere University states that the aim of the new university is to form new, bold and broader combinations that transgress traditional disciplinary borders. The Board also states that the structure is based on the needs of teaching and its responsiveness to stakeholders. Research activities will be organised separately through research groups. The justification for interdisciplinary education is to produce relevant knowledge that graduates will need in working life as well as an approach to a sustainable future solving wicked problems. The suggested organisational structure is based on the transition from disciplinarity to interdisciplinarity.

To understand the different concepts related to more than one discipline interacting in education or research, we need to examine the concepts of disciplinarity, crossdisciplinarity, interdisciplinarity, multidisciplinarity and transdisciplinarity (Tress et al. 2005; Stember 1991). A discipline may be defined as a particular academic area of study which has particular identifiable characteristics. Within an academic discipline, there are generally believed to be shared goals and a set of theories and epistemologies but 
relatively little cooperation with other disciplines (Becher and Trowler 2001). Through their research activities, disciplines are "orientated towards one specific goal, looking for an answer to a specific research question" (Tress et al. 2005, 15). Disciplines are often the basis for forming institutional structures, such as faculties, but they may also be constituents of an academic's identity since they form their own cultures. The identities of academics are based on disciplines rather than on organisations (Becher and Trowler 2001).

The disciplinary tradition has been criticised as restrictive, normative and unable to address the multifaceted aspects of real-world problems (Tress et al. 2005; Chettiparamb 2007). Attempts to overcome disciplinary limits, integrate different disciplinary approaches or even transcend the boundaries of the university are seen as viable solutions. Research and education that is not restrained to a particular discipline may be cross-, inter-, multi- or transdisciplinary. These terms have different meanings, although they are often confused or used interchangeably.

Crossdisciplinarity involves at least two different disciplines and viewing one discipline from the perspectives of others (Stember 1991). Meanwhile, multidisciplinarity involves "several different academic disciplines researching one theme or problem, but with multiple disciplinary goals" in loose cooperation, which does not cross subject boundaries to create new knowledge and theory (Tress et al. 2005, 15-16). Multidisciplinarity is the combination of multiple disciplines with a shared or common goal. The cooperation consists mostly of knowledge exchange, but theory development is still disciplinary based. Multidisciplinarity involves several researchers working together from their own disciplinary viewpoints (Stember 1991). Interdisciplinarity takes the multidisciplinary approach further by crossing disciplinary boundaries and uniting them with common goal-setting. Interdisciplinarity encompasses the development of integrated theories and epistemologies. Transdisciplinary is similar to interdisciplinarity, but it extends the disciplinary, scientific and academic boundaries, integrating both academic disciplines and nonacademic stakeholders. Knowledge and theories are developed through cooperation between academia and society, with common goal-setting 
by actors from different disciplinary and organisational backgrounds, which may be academic or non-academic (Tress et al. 2005).

Recent research has questioned the social relevance of traditional engineering education, especially in addressing wicked problems (Edström 2017; Lönngren 2017). According to Lönngren (2017, 32) "the existence of a strong engineering paradigm seems to create a disciplinary culture in which diversity of perspectives and worldviews is not highly valued." Moreover, engineering education has been criticised for a lack of social relevance and ignoring social, political and environmental issues or reallife problems (Denis and Heap 2012, 265). Thus, the aim of breaking down disciplinary cultures and introducing other disciplinary perspectives would seem fruitful in increasing the social relevance of technical education. A new multidisciplinary university with interdisciplinary faculties would enable technical education to increase beneficial interactions with other disciplines. Both terms "multidisciplinarity" and "interdisciplinarity" are used in relation to the Tampere University merger, and it is not always clear if a distinction is made between these. In our discussion, we have chosen to use the term "interdisciplinary." However, despite the term used, an approach that transgresses the disciplinary boundaries is advocated in the new university and its organisational structure.

\section{Interdisciplinarity in Higher Education Mergers in Finland}

Higher education mergers in Western Europe and Nordic countries in particular have been used as policy instruments for restructuring higher education systems and meeting the goals of higher education policies (Pinheiro et al. 2016). Mergers may also be motivated by the need to increase responsiveness to environmental changes and the expectations of societal stakeholder groups. In practice, these demands have called for increased size and enhanced internal diversity, for example, by exploring interdisciplinary synergies (Pinheiro et al. 2016). In previous studies, the concept of discipline has been seen as integral for the success of a merger process. Previous research (Harman and Harman 2003; Pinheiro et al. 2016) indicate that 
institutions with similar disciplinary structures tend to be culturally more difficult to merge than institutions that are from different disciplinary backgrounds or merged across higher education sectors. Nevertheless, disciplinary structure plays an important role in the merger process, where the aim can be the consolidation of similar types of academic portfolios or creating synergies by combining different types of disciplinary profiles.

Although increasing interdisciplinarity seems to be a "typical suspect" in justifying merger processes, it has not been the most common one in restructuring the Finnish higher education landscape. The Finnish government has initiated a series of mergers since the mid-2000s, termed "the structural development of the Finnish higher education system," with the premise of making Finnish higher education more reactive to global changes (Välimaa et al. 2014). Aarrevaara and Dobson (2016) analysed the main goals of the Finnish merger processes until 2015 in universities of applied sciences (five mergers) and universities (five mergers). Interdisciplinarity was only a stated goal in two out of ten mergersAalto University and Tampere University of Applied Sciences. In the latest 2019 merger, the Tampere 3 merger, interdisciplinarity is a central aim.

The most significant forerunner is the Aalto University merger, which involved the Helsinki School of Economics, Helsinki University of Technology and the University of Arts and Design Helsinki. This combination of three distinctive fields was intended to create an innovative interdisciplinary and responsive university. Aalto has been an initiator in building a bridge between interdisciplinarity and excellence. As Aula and Tienari (2011) note, since the outset of the Aalto branding campaign, coincidentally or not, other universities in Finland have also branded themselves as "leading multidisciplinary international institutions." Aalto has become a showcase of Finnish innovative knowledge society and practical interdisciplinary industry-university collaboration (Aula and Tienari 2011). This leads to the hypothesis that a multidisciplinary merger with increased interdisciplinarity should increase the relevance, innovativeness and international competitiveness of all fields, including technical education. This also implies that external stakeholders expect mergers to enhance knowledge production and meet the needs of industry and regional stakeholders (Välimaa et al. 2014, 42). 
In our other research, we discovered that education and research at Tampere University of Technology were already perceived as interdisciplinary by academics in the university (Vellamo et al. forthcoming). In the new university structure, technical education will not form one or several separate faculties but will be dispersed in five faculties with other disciplines of the comprehensive university. Administratively, this could lead to large faculties, with varied degree programmes (e.g., theatre studies and computer science) being led by one dean. As the stated aim also includes educational cooperation, this has raised questions about identifying shared educational content that will be relevant to disciplines as different as arts and engineering. An interdisciplinary organisational structure was chosen to increase the relevance of educational programmes from the perspective of stakeholders and to strive to become a socially responsible university (see also Chap. 6). This presupposes that the disciplinary-based organisational structure of the merging universities has not contributed to interdisciplinarity and that the new multidisciplinary structure would stimulate cooperation between different disciplines. This would also lead the faculties to provide education better suited to addressing wicked problems and more responsible to higher education stakeholders.

\section{Defining the Stakeholders}

The faculty structure of the new university combines different disciplines into faculties based on the needs of educational development and shared themes. However, from the proposals, it is unclear how and by whom these themes have been defined. According to the feedback, neither the academics nor the students of these fields were consulted, and the shared themes did not arise from previous cooperation between the fields. In the plan, no particular resources or other instruments for increasing interdisciplinarity are mentioned; it appears that simply placing different disciplines into the same organisational units is expected to lead to interdisciplinarity in education.

When we examined both the justifications of the faculty structure proposal and the feedback on it, we anticipated that several different stake- 
holders would be mentioned. We were able to identify five main stakeholders: students, academics, institution, industry and region/ nation (cf. Esfijani et al. 2013; Tetrevova and Sabolova 2010). The staff provided most of the feedback, and even though they do not mention themselves as a stakeholder group, it is clear that their interests are important and that the university is responsible to them. The university itself was referred to as a stakeholder several times, although this can often be traced back to the academics. We have labelled one of the stakeholders as the nation/region; however, based on empirical analysis, a nation is defined primarily from the viewpoint of the national economy rather than from a social or legal perspective. This refers to economic and innovative competitiveness at the local, national and global levels, for which technical education is responsible. The stakeholders, the university's responsibility towards them and the possible benefits if the disciplinary approach is transgressed are presented in the following table. Interdisciplinarity has become a normative perspective in higher education policy, and many stakeholders, such as national and international funding bodies, research councils and ministries, are pushing towards interdisciplinarity through financial steering.

In sum, it seems that a more interdisciplinary approach should be beneficial to all stakeholders by increasing the university's responsibility to each stakeholder in different positive ways. In the following sub-chapters, we look at the different aspects of university responsibility to different stakeholders and the effects the new interdisciplinary organisational structure is expected to have on these stakeholders, as perceived by the students and faculty. However, while Table 8.1 presents interdisciplinarity as positive for these stakeholders, the reality might be different. In addition, the stakeholders themselves are presented as monolithic entities with a set of well-defined interests, although they have different views, conflicting interests and multiple stakeholders are represented as a single group. In many ways, we are simplifying the stakeholders, the university's responsibility towards them and their idealised disciplinary stance. With stakeholders such as institutions, we are referring to the meso level of the organisation, acknowledging that this does not actually represent the different parts and levels or members of the organisation. 
Table 8.1 Summary of the main stakeholders, university responsibilities towards them and what interdisciplinarity could provide for them

\begin{tabular}{lll}
\hline Stakeholder & University responsibility & Idealised interdisciplinarity \\
\hline Students & Applicable knowledge & Different (inter)disciplinary \\
& Skills for working life & perspectives \\
& Relevant degree & Transferrable soft skills \\
& Employability & New attractive interdisciplinary \\
& Attractive study choice for & degree programmes for students \\
& prospective students & \\
Academics & Attractive workplace for top & Interdisciplinary teaching \\
& academics & cooperation \\
& Good resources for teaching & Cooperating across disciplines in \\
& and research & interdisciplinary research groups \\
Institution & Institutionally high-ranked & Attractive and competitive, new \\
& university & and innovative interdisciplinary \\
& Other institutions as partners & university \\
& and competitors & \\
Industry & Providing highly skilled & Involved in teaching and research \\
& workforce & Crossing university boundaries \\
& Cooperation in teaching and & \\
& research & \\
& Social innovations & \\
Region/ & Local to global & Innovation system crossing the \\
nation & competitiveness & university boundaries \\
& Innovations & \\
& National economy & \\
\hline
\end{tabular}

\section{Responsibility Towards Students}

The staff and student responses indicate that the primary responsibility of the university and technical education is to students and prospective students or applicants. Technical education, as carried out by the technical university, is described as attractive to applicants and having high-quality teaching. These aspects may be threatened in the new university because of the new faculty structure or because the proposed names of the faculties may be misleading. The following quotes highlight concerns about the attractiveness of technical education in Tampere for future students:

$[\mathrm{H}]$ ow well will the engineering degree programs placed in different faculties fare in the national student applications? They might, no doubt, inter- 
est new applicant groups, but most likely not the traditional applicants. (Comments on the second proposal)

If this new faculty structure is carried out, it is certain that Tampere3 remains a second option for [Information and Communication Technology] ICT students compared to the universities of Helsinki and Aalto paddling way ahead. (Comments on the first proposal)

For the fields of engineering, the new structure will make it difficult for applicants to choose which program to apply to, and make Tampere3 a less attractive place. (Comments on the first proposal)

From the above feedbacks, it appears the applicants may not recognise or appreciate technical education in the new university because of the organisational structure. It is surprising that applicants would emphasise the organisational structure and faculty names rather that the content and names of the degree programmes. According to these responses, there is a risk that applicants may choose another (technical) university in Finland (e.g., Aalto), where technical education is perceived as more traditionally or visibly present. In the quotes, information and communication technology (ICT) is a field where there is thought be competition between Tampere and other universities offering technical education. These arguments suggest that future students find a traditional disciplinary structure more appealing and prestigious and would not appreciate a more interdisciplinary organisational structure.

Based on the comments, the current and future students' identities as technical students and their trust in the quality of their education may also be in jeopardy: "We believe the proposed structure will dilute the requirements for study attainments because of the disparity between the fields in the proposed faculty on evaluating credit points and to the degradation of the technical identity of students" (Statement of the Student Guild Indecs and Manager). Here, technical education is presented as demanding and requiring rigorous study, whereas other fields are implicitly less demanding and thus do not have the same prestige. Hence, a more interdisciplinary education might dilute the content and value of technical degree programmes. 


\section{Responsibility Towards Industry}

Several passages highlight the responsibility of technical education to industry stakeholders and companies. This responsibility of working life relevance seems particular to technical education, as this aspect was not raised in the feedback relating to other fields.

According to the responses, grouping the technical degree programmes into the same faculties with degree programmes from other fields may put the responsibility to industry at risk. The respondents fear that the inclusion of common courses might dilute the content of the technical degree, and graduates would no longer have the technical skills demanded by industry. Another concern is that the perception that companies have of the reputation and brand of the current technical degrees might be diminished, therefore making companies unwilling to hire graduates or to cooperate with the faculty in research or teaching. For example, companies will not cooperate with faculties that do not appear technical enough and will not hire Masters of Science graduates from a "faculty of humanities" (comments on the first proposal). According to one respondent, "The appreciation of industrial management and knowledge management in the working market needs to be secured by keeping the brand of these degree programs focused on technology" (comments on the first proposal). Hence, it seems that industry primarily appreciates technological knowledge, not interdisciplinary degrees or soft transferrable skills. However, this represents the view the respondents, academics and students have on industry stakeholders. The respondents worry that the faculty structures are planned without knowledge of the industry stakeholders' needs. Indeed, there were requests to ask stakeholders what they expect from technical education and how the teaching of these skills should be organised: "please contact local industry like Valmet, Insta, Cargotec, Sandvik and ask what type of M.Sc. students they need" (comments on the first proposal).

Those commenting on the proposed faculty structure do not see the interdisciplinary combination of technical degree programmes with degree programmes from other non-technical fields as a positive development. They fear that industry stakeholders will not recognise this kind of technical degree. In addition, there are worries that the content of the 
degrees might become less technology-focused. Overall, the respondents are concerned that these changes might result in such a drastic transformation that graduates would no longer constitute a suitable workforce for companies, thereby risking the competitiveness of the whole nation: "This way Tech industry will disappear from Finland" (comments on the first proposal).

The Transitionary Board that prepared the new faculty structure did not ask comments from external stakeholders (e.g., companies). The Board wrote the proposal and then asked for comments from the faculty and students and internal bodies of the three merging institutions. The Board itself is supposed to represent external stakeholders, with members from companies and other investors such as the city of Tampere. However, in the comments on the faculty proposal, the Board is criticised for not knowing what external stakeholders want. The respondents do not consider the Transitionary Board a well-known and respected stakeholder and thus do not consider its proposals legitimate (cf. Geschwind 2018).

\section{Institutional Responsibility as Responsibility Towards Academics?}

Many respondents see the university and technical education as competing with other universities globally and nationally. The respondents mention Aalto most frequently, but also Lappeenranta University of Technology, the University of Oulu and the University of Turku as the national competitors. Other Finnish universities offering technical degree education are viewed as taking advantage of the perceived decrease in the role of technology at Tampere: "Nationally there are investments made in technical education in e.g. Lappeenranta, Oulu and Turku. If technology is not really strong and visible in the profile of the new university, the focus will move to these other universities in Finland" (Petition for the Stand of Technology by the Student Union).

The references to Aalto as the main competitor in technical education are interesting, as Aalto has been branded a multidisciplinary university. However, it is still strongly associated with the former Helsinki University 
of Technology (Aula and Tienari 2011). In the responses, Aalto is also regarded as an example of not choosing a multidisciplinary structure in the merger but keeping separate schools. Some respondents see this as a form of appreciation of the different disciplines: "For example, in Aalto, they did not combine arts and technology by force, but gave both their own value and position as independent" (comments on the first proposal). Some responses use Aalto as a point of comparison from a critical perspective: "The main mistake made in Aalto was not creating a clear ICT focus area. This is a mistake that should not be repeated in Tampere ... the ICT-field could become a crown jewel in the new university" (comments on the second proposal).

The proposed structure of the new university is criticised for hiding technology amongst multi-disciplinary faculties, which degrades the internal cooperation of different technical fields (especially different strands of ICT). Some respondents also criticised the naming of the faculties in a way that does not clearly indicate that they provide technical education, particularly in comparison to national and international counterparts, including prestigious universities such as MIT and Delft. It is argued that well-known and functioning models should be adopted rather than inventing completely novel structures, which are not selfevident to students, academics or external stakeholders: "In top-notch [technical] universities, there is an ICT faculty" (comments on the second proposal). Many respondents thus advocate for a recognisable academic discipline and an organisational structure based on it (cf. Becher and Trowler 2001). The respondents argue that the stakeholders want a disciplinary structure, and this is important for the university's prestige, although it seems that the academics are the ones advocating for a traditional disciplinary-based organisation.

The comments indicate that high-ranked universities, such as MIT, epitomise the ideal structure that the new university should emulate. It seems that universities that are not highly ranked globally cannot be trailblazers in creating new structures, faculty names and degree programmes but should follow more traditional and recognisable models and the example of world-class universities (cf. Geschwind 2018). The Board did not use this emulation of role models as a justification for either the merger or structure, although it seems that the staff and students would have found this legitimate. Those who gave feedback identified universities 
that should have been benchmarked when planning the new structure. However, other universities were only mentioned as models in the comments concerning technical education. As Geschwind $(2018,12)$ notes, "there are indicators that the technical universities to a higher degree refer to a market related logic, including e.g. position, branding and competitors within the same organizational sub-field." Thus, it may be argued that institutional responsibility towards stakeholders is particularly important for technical education.

It seems that the university's ranking and prestige matter to external stakeholders but even more to the internal stakeholders and academic staff. The academics seem to fear that the university will lose its prestige and become a less attractive workplace for top researchers. In addition, the lower ranking of the university could affect the appreciation the academics themselves receive globally. Many of the respondents represent the technical university as an entity and a stakeholder, although it is problematic to present the organisation as a monolithic entity with a set of welldefined interests. In many cases, it seems that the actual stakeholder whose interests are presented as those of the university is the academic staff of a particular field. Academics associate themselves with the organisation, and if the status of the university is compromised, their academic identities are threatened. Indeed, Välimaa et al. (2014, 45-46) argue that the loss of academic identity may be a consequence of a merger. They note that there may be resistance, as academics see the merger as a "top-down organizational reform rather than an organic, bottom-up development."

\section{Responsibility Towards Region and Nation}

The increasing role of the university in the local community is reflected in the growing importance of university social responsibility (Chapleo and Simms 2010). The responsibility to the nation and region regarding technical education mostly relates to the national or local economy rather than to civil society. Many of the comments highlight the role of the technical university in securing competitiveness with industry stakeholders by creating local innovation systems. This viewpoint is especially prominent in relation to ICT: 
Tampere is a major national and international centre of the ICT industry, including software applications, games and until recently mobile communications and networks .... Tampere University should be organised to meet this need, should forge strong relationships with local companies and make computer science and related disciplines a key part of its educational profile. The alternative is to risk these companies relocating to other places in Finland that can serve their needs better, and where they can compete for the graduates on offer. (Comments on the first proposal)

This quote refers to the industry, the Tampere region and Finland as stakeholders. It seems that failing the responsibility towards industry ultimately means that the university does not serve its local and national stakeholders, which may threaten national and regional competitiveness.

Technical education is more responsible to the local and national economies than other fields, and any perceived weakening of technical education would thus have a negative effect: "The role of technology is weak in the proposal and if it is carried out, the structure will harm the education and research in technical fields in Tampere and through this the whole local economic life and competitiveness" (comments on the second proposal). Strong technical education (here ICT) is seen as crucial to economic growth and sustainability: "If we look into the future of Finland and industry in the Tampere region, it only grows significantly because of ICT fields ... that is why T3 needs a really strong, visible and prominent ICT faculty!" (comments on the second proposal). Another comment expresses a similar view: "IT industry is one of the cornerstones in industry in the Tampere region, and its societal and economic relevance will not dwindle in the long run (on the contrary). Taking this into account, it seems unbelievable that the proposed faculty structure aims at hiding IT fields" (comment on the second proposal).

In these comments, the Tampere region and Finland are seen as the stakeholders; however, they are quite abstract, and the responsibility towards them is also an abstract concept. Competitiveness cannot be traced back to a particular actor but is closely related to industry. It is also clearly something that the university and technical education can provide to its stakeholders; therefore, any perceived weakening of technical 
education may threaten the sustainability of the local and national economies.

\section{Intertwined Responsibilities}

It was not easy to distinguish the different stakeholders to whom technical education is responsible, as they were often linked to each other in the answers. For example, internationally competitive degree programmes, which are relevant to industry, are also attractive to students. The most reoccurring stakeholders were industry and students. It seems obvious that students would be considered an important stakeholder group (cf. Chapleo and Simms 2010). However, it should be noted that the students gave comments on the proposals, which could heighten the importance of the student perspective.

From what is known about the identity of technical education, companies and industry stakeholders are also considered very important. Of the abovementioned stakeholders, industry is the one mentioned most often in the responses. In addition, the regional and national stakeholders often seem to be linked to industry, which further increases the importance of industry as a stakeholder.

However, the most important stakeholders are the academics and the university, as the brand, ranking, prestige and competitiveness of the institution are relevant to itself and all the other stakeholders. In effect, it seems that the university must be responsible to itself to be responsible to other stakeholders. In the responses, the university is represented as a unified organisational entity, perhaps to enhance the impact of the academic staff in technical fields or to hide the otherwise clear self-interest. Importantly, most of the comments were made by the staff of the merging institutions. Thus, the views of the staff are represented in the answers, even though they seldom name themselves as a stakeholder group. Some of these views are also represented as being those of the external stakeholders, while in reality they serve the interests of the academics.

The importance of different stakeholders is often attributed to their financial role in the university or their "potential impact on the strategic direction of the organisation" (Chapleo and Simms 2010, 8). There are also 
other stakeholders more directly related to the funding of higher education, including the government, ministry, funding bodies or taxpayers. Even though the government was identified in the theoretical part as one of the most salient stakeholders (cf. Benneworth and Jongbloed 2010), it is mentioned in few responses, and when it is, only in relation to the competitiveness and profiling of universities.

In sum, it can be argued that the respondents do not agree with the Transitionary Board on the benefits of interdisciplinarity. Instead, they argue that an interdisciplinary structure threatens the responsibility of technical education to its main stakeholders (Table 8.2).

It seems that if technical education had continued in a technical university or at least in faculties only providing Master of Science (Technology) education, it could meet its responsibilities and the demands of its stake-

Table 8.2 Summary of the aspects interdisciplinarity is considered to jeopardise from the perspective of technical education stakeholders

\begin{tabular}{lll}
\hline Stakeholder & University responsibility & Interdisciplinarity jeopardises \\
\hline Students & Applicable knowledge & Less technical knowledge, less \\
& Skills for working life & demanding studies \\
& Relevant degree & Less prestigious degree \\
& Employability & Employability of \\
& Attractive study choice for & graduates decreased \\
& prospective students & Less attractive choice for \\
& applicants \\
Academics & Attractive workplace for top & Less attractive as a workplace \\
& academics & Academics' reputation \\
& Good resources for teaching & influenced by lower ranking \\
& and research & Resources must be shared with \\
& & other disciplines \\
Institution & High-raked top university & Not resembling high-ranked top \\
& Technical university & universities \\
& & Loses identity as technical \\
& & university \\
Industry & Providing highly skilled & Less willing to hire graduates \\
& workforce & Less willing to cooperate in \\
& Cooperation in teaching and & teaching and research \\
& research & Technical breakthrough in \\
& Innovations & industry less likely \\
Region/ & Local to global & Competitiveness decreased \\
nation & competitiveness & Economic growth curbed \\
& National economy & \\
\hline
\end{tabular}


holders and it would have particularly be in the interest of the academic staff in technical fields. The technical university academics and students think the association with softer disciplines will negatively affect the perceptions of the stakeholders of technical education. Mainly, they feel that the faculty structure threatens the responsibility of technical education and the university as an institution.

Strong disciplinary fields and organisational structures based on them are perceived to improve interdisciplinary cooperation: "The current strong degree programs in Tampere enable high-quality cross-disciplinary cooperation. For example, ICT needs to become a cross-cutting theme in the new higher education institution, but in order to have a strong knowledge base, it must be concentrated and have a firm foothold in a particular faculty. Cross-disciplinary research is only possible when there are strong enough knowledge basis" (Petition for the Stand of Technology by the Student Union). Thus, the relevance of technical education is based on a strong disciplinary foundation, and interdisciplinarity is not considered to provide added value to the stakeholders.

It may be concluded that the responsibility of technical education to its stakeholders may be threatened, at least according to the respondents, students and academic staff.

\section{Conclusion: Is Technical Education in Jeopardy?}

In this chapter, we analysed reactions to the proposal of interdisciplinary faculty structures aimed at increasing the societal impact of the university. In addition, following the different aspects of university responsibility, we examined how the proposed changes were seen to affect the societal impact of technical education in relation to its stakeholders. We identified the main stakeholders mentioned most often in the comments on the proposals and analysed the respondents' views on the stakeholders' expected reactions to the changes.

Based on different aspects of disciplinarity and the idea of becoming increasingly responsible through interdisciplinary approaches, the notion of a new interdisciplinary university, where different disci- 
plines are placed in productive cooperation within the organisational structure, seemed like an approach to increase the social relevance of all educational fields, including technical education. This is particularly relevant, as technical education has been criticised for being unable to tackle the so-called wicked problems through its disciplinary approaches. However, the respondents do not perceive it in this way and feel that disciplinary-based technical education meets the needs of its stakeholders. It is interesting that they do not refer to the main justification for the interdisciplinary structure, namely, better addressing wicked problems. Even though they do not mention wicked problems in their feedback, they claim that technical education is already socially responsible and meets the needs of its main stakeholders. However, these respondents are staff and students and thus internal stakeholders. They claim to speak for the external stakeholders and justify their views by referring to the needs of external stakeholders and the university's responsibility towards them. It appears the respondents are threatened by the new organisational structure and therefore argue for keeping the traditional organisational status quo or making changes aligned with their strategic interests (e.g., ICT as a core area).

We conclude that an interdisciplinary structure is not thought to increase the responsibility of technical education to its stakeholders. Therefore, the intended increase in societal impact and the university's enhanced capability to contribute to solving wicked problems are questionable. The respondents argue for old structures and disciplinary divisions and claim that the visibility and appreciation of technical education would remain higher in a technical university or in separate technical faculties. The respondents view the traditional disciplinary approach as both organisationally clear and consistent with the needs of stakeholders. They were also critical of the planning process and the top-down way the Transitional Board imposed the interdisciplinary structure without consulting internal or external stakeholders. Moreover, they did not think that any disciplinary structural change should be made from the perspective of stakeholders' needs. These internal actors feel threatened 
by the new arrangements, arguing for "no change" based on the perceived needs of external stakeholders and important blueprints (e.g., Aalto or MIT).

Despite the theoretically positive views on interdisciplinarity increasing cooperation beyond the borders of the university, the current disciplinary approach is seen as functional and serving the stakeholders to whom the university is responsible. Meanwhile, the interdisciplinary structure is perceived to threaten the existing responsibilities of technical education. The respondents also view technical education as a whole and specific field that is in jeopardy because of the anticipated reactions of the key stakeholders - the stakeholders may not recognise or appreciate technical education if the traditional organisational structure is changed. Here, we have only examined the responses of staff and current students in technical fields, but it would be very interesting to explore some of the external stakeholders' views on the proposed structure.

Time will show whether interdisciplinary faculties increase educational cooperation between different disciplines, how different stakeholders react to these structural changes and whether the responsiveness of technical education to its stakeholders is compromised. It will also be possible to evaluate whether the interdisciplinary structure, even though realised in a compromised way, will increase cooperation between different disciplines and enable knowledge and education better suited to solving wicked problems.

It is not surprising that internal stakeholders, who have their own selfinterests, oppose structural changes that jeopardise the disciplinary bases of their academic identities. However, it is interesting that they justify their claims through the needs of external stakeholders. The organisational change threatens the identities of academics, which are often based on the disciplinary structures, university identity and status quo. It seems that university leaders as well as national higher education policies promoting and implementing interdisciplinarity will encounter resistance from academics in most disciplines. When examining the data on this particular structural change in a merger process, academics in technical fields seem to be most reluctant to move from disciplinary structures to interdisciplinary structures. 
Universities have the responsibility to meet the needs of their stakeholders, but there are conflicting views on these needs from national, institutional and disciplinary perspectives. Consequently, universities oscillate between disciplinary approaches and institutional interdisciplinarity policies to meet stakeholder needs. This may compromise their ability to be responsible to stakeholders, and there is no shared understanding of which approach would improve university social responsibility.

Acknowledgements We would like to thank Professor Jussi Kivistö from Tampere University for his constructive comments on this chapter.

\section{Appendix 1: List of analysed documents and data}

First suggestion of the faculty structure of Tampere University by the Board of the University Foundation (24 Nov 2017)

Updated suggestion of the Faculty structure of Tampere University by the Board of the University Foundation (8 Dec 2017)

The Technical University of Tampere Academic Board's feedback on the faculty structure suggestion (18 Dec 2017)

Statement of the Board of Managers of TUT and UTa

Strategy Statement (2 Feb 2018)

The Student Union's response to suggestions on the faculty structure (1 Dec 2018)

Petition for the Stand of Technology by the Student Union (16 Dec 2017)

Statement by TEK Labour Union for technical fields (online statement)

University regulations of Tampere University (draft)

University regulations of Tampere University (accepted on 10 Feb 2018)

Tampere3 strategy (proposal)

Appendix to the Tampere3 strategy (2 Jan 2018)

Feedback collected within the universities (staff and students) on the first faculty structure proposal in Finnish and in English (24-30 Nov 2017) https:// wiki.tamk.fi/pages/viewpage. action? pageld=93684095

Feedback collected within the universities (staff and students) on the second faculty structure proposal in Finnish and in English (11-18 Dec 2017) https:// wiki.tamk.fi/pages/viewpage. action?pageld=93684095

Feedback from the Deans of TUT and UTa (26 March 2018) on the faculty structure of Tampere University by the Board of the University Foundation dated on 2 Jan 2018

Board of Faculty of Computing and Electrical Engineering (7 Dec 2017)

Statement of the Student Guild Indecs and Manager 


\section{Appendix 2: Faculty proposals and distribution of fields}

\begin{tabular}{|c|c|}
\hline Faculty & Fields \\
\hline \multicolumn{2}{|l|}{ First proposal 24 Nov 2017} \\
\hline $\begin{array}{l}\text { Communication and } \\
\text { Data Sciences }\end{array}$ & $\begin{array}{l}\text { Communications, journalism, languages, software } \\
\text { engineering/production, signal processing, } \\
\text { information studies, literature, theatre studies }\end{array}$ \\
\hline $\begin{array}{l}\text { Engineering Sciences } \\
\text { and Architecture }\end{array}$ & $\begin{array}{l}\text { Communications system engineering, electrical } \\
\text { engineering, automation engineering, mechanical } \\
\text { engineering, materials science, civil engineering, } \\
\text { architecture }\end{array}$ \\
\hline $\begin{array}{l}\text { Technical and Natural } \\
\text { Sciences }\end{array}$ & $\begin{array}{l}\text { Mathematics, physics, chemistry, computer science, } \\
\text { statistics }\end{array}$ \\
\hline $\begin{array}{l}\text { Biomedicine and Health } \\
\text { Technology }\end{array}$ & $\begin{array}{l}\text { Medicine, biomedicine, health sciences, psychology, } \\
\text { logopedia }\end{array}$ \\
\hline Educational Sciences & $\begin{array}{l}\text { Education, pedagogics, early childhood education, } \\
\text { vocational education }\end{array}$ \\
\hline Business and Leadership & $\begin{array}{l}\text { Business, administrative science, knowledge } \\
\text { management, industrial management }\end{array}$ \\
\hline Social Sciences & $\begin{array}{l}\text { Social sciences, philosophy, political science, social } \\
\text { work, history }\end{array}$ \\
\hline \multicolumn{2}{|c|}{ Second proposal 8 Dec 2017} \\
\hline $\begin{array}{l}\text { Communication and } \\
\text { Data Sciences }\end{array}$ & $\begin{array}{l}\text { Communications, journalism, data sciences, } \\
\text { information studies, software engineering/ } \\
\text { production, artificial intelligence and machine } \\
\text { learning }\end{array}$ \\
\hline $\begin{array}{l}\text { Technical and Natural } \\
\text { Sciences }\end{array}$ & $\begin{array}{l}\text { Mathematics, physics, chemistry, telecommunications } \\
\text { technology, signal processing, electrical } \\
\text { engineering, automation engineering, mechanical } \\
\text { engineering, materials science }\end{array}$ \\
\hline $\begin{array}{l}\text { Environmental } \\
\text { Engineering and } \\
\text { Architecture }\end{array}$ & $\begin{array}{l}\text { Civil engineering, architecture, environmental } \\
\text { engineering, energy technology }\end{array}$ \\
\hline $\begin{array}{l}\text { Medicine and Health } \\
\text { Technology }\end{array}$ & $\begin{array}{l}\text { Medicine, biomedical technology, biotechnology, } \\
\text { health technology }\end{array}$ \\
\hline $\begin{array}{l}\text { Educational Sciences } \\
\text { and Culture }\end{array}$ & $\begin{array}{l}\text { Educational sciences, pedagogics, languages, } \\
\text { literature, theatre studies }\end{array}$ \\
\hline Business and Leadership & $\begin{array}{l}\text { Business, administrative science, knowledge } \\
\text { management, industrial management, political } \\
\text { science }\end{array}$ \\
\hline Social Sciences & $\begin{array}{l}\text { Social sciences, philosophy, history, social work, } \\
\text { health sciences, psychology, logopedia }\end{array}$ \\
\hline
\end{tabular}




\begin{tabular}{|c|c|}
\hline Faculty & Fields \\
\hline \multicolumn{2}{|c|}{ Structure decided on 7 June 2018} \\
\hline $\begin{array}{l}\text { Information Technology } \\
\text { and Communication } \\
\text { Sciences }\end{array}$ & $\begin{array}{l}\text { Electrical engineering, information technology, } \\
\text { communications, languages }\end{array}$ \\
\hline $\begin{array}{l}\text { Management and } \\
\text { Business }\end{array}$ & $\begin{array}{l}\text { Business, administrative science, knowledge } \\
\text { management, industrial management, political } \\
\text { science }\end{array}$ \\
\hline Education and Culture & Educational sciences, pedagogics \\
\hline $\begin{array}{l}\text { Medicine and Health } \\
\text { Technology }\end{array}$ & $\begin{array}{l}\text { Medicine, biomedical technology, biotechnology, } \\
\text { health technology }\end{array}$ \\
\hline Built Environment & Architecture, civil engineering \\
\hline $\begin{array}{l}\text { Engineering and Natural } \\
\text { Sciences }\end{array}$ & $\begin{array}{l}\text { Physics, materials science, environmental } \\
\text { engineering, automation engineering, mechanical } \\
\text { engineering, biomedical technology, biotechnology }\end{array}$ \\
\hline Social Sciences & $\begin{array}{l}\text { Social sciences, philosophy, history, social work, } \\
\text { health sciences, psychology, logopedia }\end{array}$ \\
\hline
\end{tabular}

\section{References}

Aarrevaara, T., \& Dobson, I. (2016). Merger Mania? The Finnish Higher Education Experience. In R. Pinheiro (Ed.), Mergers in Higher Education, Higher Education Dynamics (Vol. 46). Switzerland: Springer International Publishing.

About the United Nations Sustainable Development Goals. (2015). Retrieved April 5, 2019, from https://www.un.org/sustainabledevelopment/sustainabledevelopment-goals/.

Aula, H.-M., \& Tienari, J. (2011). Becoming World-Class? Reputation-Building in a University Merger. Critical Perspectives on International Business, 7(1), 7-29.

Becher, T., \& Trowler, P. (2001). Academic Tribes and Territories: Intellectual Enquiry and the Culture of Disciplines (2nd ed.). Buckingham: The Society for Research into Higher Education and Open University Press.

Benneworth, P., \& Jongbloed, B. W. (2010). Who Matters to Universities? A Stakeholder Perspective on Humanities, Arts and Social Sciences Valorization. Higher Education, 59(5), 567-588.

Brown, V. A., Deane, P. M., Harris, J. A., \& Russel, J. Y. (2010). Towards a Just and Sustainable Future. In V. A. Brown, J. A. Harris, \& J. Y. Russel (Eds.), Tackling Wicked Problems Through the Transdisciplinary Imagination. London and Washington, DC: Earthscan. 
Chapleo, C., \& Simms, C. (2010). Stakeholder Analysis in Higher Education: A Case Study of the University of Portsmouth. Perspectives: Policy and Practice in Higher Education, 14(1), 12-20.

Chettiparamb, A. (2007). Re-Conceptualizing Public Participation in Planning: A View through Autopoiesis. Planning Theory, 6(3), 263-281.

Denis, A. B., \& Heap, R. (2012). Social Relevance and Interdisciplinarity in Canadian Engineering Education. In A. Beraud, A. S. Godfroy, \& J. Michel (Eds.), GIEE 2011: Gender and Interdisciplinary Education for Engineers (pp. 255-266). Sense Publishers.

Edström, K. (2017). Exploring the Dual Nature of Engineering Education: Opportunities and Challenges in Integrating the Academic and Professional Aspects in the Curriculum. PhD dissertation, Stockholm.

Esfijani, A., Hussain, F., \& Chang, E. (2013). University Social Responsibility Ontology. Engineering Intelligent Systems, 4, 271-281.

Ferlie, E., Fitzgerald, L., Mcgivern, G., Dopson, S., \& Bennett, C. (2011). Public Policy Networks and "Wicked Problems": A Nascent Solution? Public Administration, 89(2), 307-324.

Geschwind, L. (2018). Legitimizing Change in Higher Education: Exploring the Rationales Behind Major Organizational Restructuring. Higher Education Policy, 22(3), 381-395.

Gibbons, M., Limoges, C., Nowotny, H., Schwartzman, S., Scott, P., \& Trow, M. (1994). The New Production of Knowledge. The Dynamics of Science and Research in Contemporary Societies. London: Sage.

Harman, G., \& Harman, K. (2003). Institutional Mergers in Higher Education: Lessons from International Experience. Tertiary Education and Management, 9, 29-44.

Head, B. W., \& Alford, J. (2015). Wicked Problems: Implications for Public Policy and Management. Administration and Society, 47(6), 711-739.

Hsieh, H.-F., \& Shannon, S. E. (2005). Three Approaches to Qualitative Content Analysis. Qualitative Health Research, 15(9), 1277-1288.

Jackson, A. Y., \& Mazzei, L. A. (2012). Thinking with Theory in Qualitative Research: Viewing Data Across Multiple Perspectives. New York: Routledge. Kogan, M., \& Teichler, U. (2007). Key Challenges to the Academic Profession. Kassel: Jenior.

Lönngren, J. (2017). Wicked Problems in Engineering Education: Preparing Future Engineers to Work for Sustainability. PhD dissertation, Gothenburg, Sweden. 
Lyytinen, A., Kohtamäki, V., Kivistö, J., Pekkola, E., \& Hölttä, S. (2017). Scenarios of Quality Assurance of Stakeholder Relationships in Finnish Higher Education Institutions. Quality in Higher Education, 23(1), 35-49.

Pinheiro, R., Geschwind, L., \& Aarrevaara, T. (Eds.). (2016). Mergers in Higher Education: The Experience from Northern Europe. Higher Education Dynamics. Cham/Heidelberg/New York/Dordrecht \& London: Springer International Publishing.

Ramaley, J. A. (2014). The Changing Role of Higher Education: Learning to Deal with Wicked Problems. Journal of Higher Education Outreach and Engagement, 18(3), 7-22.

Stember, M. (1991). Advancing the Social Sciences Through the Interdisciplinary Enterprise. Social Science Journal, 28(1), 1-14.

Tampere University web page/News/Together we are greater. Retrieved January 7, 2019, from https://www.tuni.fi/en/news/together-we-are-greater.

Tetrevova, L., \& Sabolova, V. (2010). University Stakeholder Management and University Social Responsibility. WSEAS Transactions on Advances in Engineering Education, 7, 224-233.

Times Higher Education University Impact Rankings. (2019). Retrieved April 23, 2019, from https://www.timeshighereducation.com/rankings/impact/ 2019/overall\#!/page/0/length/25/sort_by/rank/sort_order/asc/cols/ undefined.

Times Higher Education World University Rankings / THE developing ranking based on Sustainable Development Goals. Retrieved April 5, 2019, from https://www.timeshighereducation.com/news/developing-rankingbased-sustainable-development-goals.

Tress, G., Tress, B., \& Fry, G. (2005). Clarifying Integrative Research Concepts in Landscape Ecology. Landscape Ecology, 20(4), 479-493.

United Nations Sustainable Development Goals/About. (2015). Retrieved April 5, 2019, from https://www.un.org/sustainabledevelopment/sustainabledevelopment-goals/.

Välimaa, J., Aittola, H., \& Ursin, J. (2014). University Mergers in Finland: Mediating Global Competition. New Directions for Higher Education, 2014(168), 41-53.

Välimaa, J., Papatsiba, V., \& Hoffman, D. M. (2016). Higher Education in Networked Knowledge Societies. In J. Välimaa \& D. Hoffmann (Eds.), Re-Becoming Universities? (pp. 13-39). Dordrecht: Springer.

Van de Ven, A. (2007). Engaged Scholarship: A Guide for Organizational and Social Research (1st ed.). Oxford: Oxford University Press. 
Vasilescu, R., Barnab, C., Epurec, M., \& Baicud, C. (2010). Developing University Social Responsibility: A Model for the Challenges of the New Civil Society. Procedia Social and Behavioral Sciences, 2, 4177-4182.

Vellamo, T., Siekkinen, T., Pekkola, E., \& Cai, Y. (forthcoming). Technical Identity in a Merger Process - Between a Rock and a Hard Place. In L. Geshwind, A. Broström, \& K. Larsen (Eds.), Technical Universities: Past, Present and Future. Springer.

Wan Saiful, W.-J. (2006). Defining Corporate Social Responsibility. Journal of Public Affairs, 6, 176-184.

Ylijoki, O.-H., \& Ursin, J. (2013). The Construction of Academic Identity in the Changes of Finnish Higher Education. Studies in Higher Education, 38(8), 1135-1149.

Open Access This chapter is licensed under the terms of the Creative Commons Attribution 4.0 International License (http://creativecommons.org/licenses/ by/4.0/), which permits use, sharing, adaptation, distribution and reproduction in any medium or format, as long as you give appropriate credit to the original author(s) and the source, provide a link to the Creative Commons licence and indicate if changes were made.

The images or other third party material in this chapter are included in the chapter's Creative Commons licence, unless indicated otherwise in a credit line to the material. If material is not included in the chapter's Creative Commons licence and your intended use is not permitted by statutory regulation or exceeds the permitted use, you will need to obtain permission directly from the copyright holder.

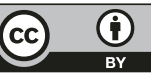

